\title{
PROGRESSOS DO MELHORAMENTO GENÉTICO DO ARROZ DE SEQUEIRO NO ESTADO DO AMAPÁ 1
}

\author{
ANDRÉ LUIZ ATROCH², ORLANDO PEIXOTO DE MORAIS ${ }^{3}$, \\ PAULO HIDEO NAKANO RANGEL ${ }^{3}$ e EMÍLIO DA MAIA DE CASTRO ${ }^{3}$
}

\begin{abstract}
RESUMO - Com o objetivo de avaliar os progressos apresentados pelas atividades de melhoramento de arroz (Oryza sativa L.) de sequeiro desenvolvidas no Estado do Amapá, são analisados dados de produção de grãos, floração média, altura de planta, classe de grãos, incidência de acamamento e doenças em sete ensaios comparativos avançados de rendimento e cinco ensaios comparativos preliminares de rendimento, conduzidos em áreas experimentais da Embrapa-Centro de Pesquisa Agroflorestal do Amapá (CPAF-AP), nos anos agrícolas 1990/91 a 1995/96. O ganho anual médio em produtividade, no período estudado, de $83,0 \mathrm{~kg} / \mathrm{ha}$, é significativo pelo teste $\mathrm{t}$ a $1 \%$ de probabilidade. Esse ganho representa, percentualmente, um incremento de $3,5 \%$ ao ano na produtividade. Das linhagens avaliadas, CNA 6843-1, CNA 8386, CNA 8394, CNA 8170 e CNA 8441 destacam-se das demais em relação às características analisadas. As linhagens CNA 6843-1 e CNA 7706 mostraram, notadamente, considerável progresso em resistência ao acamamento e qualidade de grãos, dois dos maiores problemas verificados com a cultura do arroz no Amapá. Os resultados obtidos com o presente trabalho corroboram a estratégia adotada não somente na Região Norte, mas em todo o país de desenvolver um programa cooperativo de melhoramento de arroz, que permita utilizar procedimentos seletivos baseados em informações compartilhadas por um grupo de pesquisadores que exploram áreas com certo grau de similaridade.
\end{abstract}

Termos para indexação: Oryza sativa, linhagem, ganho genético, parâmetros genéticos.

UPLAND RICE BREEDING PROGRESS IN AMAPÁ STATE, BRAZIL

\begin{abstract}
The upland rice (Oryza sativa L.) program progress in Amapá State, Brazil, is evaluated for grain yield, flowering period, plant height, lodging, disease resistance and grain type in lines from seven advanced and five preliminary tests conducted at Embrapa-Centro de Pesquisa Agroflorestal do Amapá (CPAF-AP) Experimental Station, during 1990/91 to 1995/96 crop seasons. Grain yield average annual gain of $83.0 \mathrm{~kg}$ /ha during the period is significant using t test at $1 \%$ level of probability, corresponding to $3.5 \%$ of annual increase in yield. Among the evaluated lines the CNA 6843-1, CNA 8386, CNA 8394, CNA 8170 and CNA 8441 were superior for the characters considered. CNA 6843-1 and CNA 7706, especially, showed remarkable improvement for lodging resistance and grain quality, two of the majors rice problems in Amapá. Theses results reinforce the collaborative rice breeding program strategy developed by the research institutions from the North and others regions of Brazil, based on a collaborative program by breeders that share their results from areas with similar conditions.
\end{abstract}

Index terms: Oryza sativa, genetic gain, genetic parameters, cultivar.

\footnotetext{
${ }^{1}$ Aceito para publicação em 10 de julho de 1998.

${ }^{2}$ Eng. Agr., M.Sc., Embrapa-Centro de Pesquisa Agroflorestal da Amazônia Ocidental (CPAA), Caixa Postal 319, CEP 69011-970 Manaus, AM. E-mail: atroch@cpaa.embrapa.br

${ }^{3}$ Eng. Agr., Dr., Embrapa-Centro Nacional de Pesquisa de Arroz e Feijão (CNPAF), Caixa Postal 179, CEP 74001-970 Goiânia, GO.
}

\section{INTRODUÇÃO}

A produtividade média da cultura de arroz de sequeiro no Amapá tem sido inferior a uma tonelada por hectare. Estima-se que em 1995/96 foi de apenas $800 \mathrm{~kg} / \mathrm{ha}$ (Levantamento..., 1996), apesar de o estado situar-se em uma região favorável à 
cultura no que diz respeito à pluviosidade (Morais et al., 1983). Várias são as causas possíveis dessa baixa produtividade, destacando-se entre elas a ausência quase generalizada de utilização de fertilizantes, a adoção de práticas rudimentares de manejo e o emprego de variedades tradicionais pouco produtivas e cujos grãos são de baixa aceitação comercial, tornando a orizicultura uma atividade pouco atrativa financeiramente.

$\mathrm{O}$ uso de variedades melhoradas constitui-se na técnica de menor dispêndio para o produtor e, portanto, de mais fácil adoção e com retornos econômicos em curto tempo. Pela reconhecida importância da disponibilidade de variedades adaptadas, para o desenvolvimento de uma agricultura eficiente, a Embrapa-Centro de Pesquisa Agroflorestal do Amapá (CPAF-AP) vem participando do esforço conjunto das demais unidades de pesquisa da Embrapa que atuam direta ou indiretamente na Região Norte na promoção do melhoramento genético da cultura do arroz, em particular no Estado do Amapá. Entre as atividades de pesquisa, a avaliação de linhagens de arroz tem sido objeto da maior ação cooperativa das unidades da Embrapa e das instituições estaduais de pesquisa agrícola em todo o território nacional (Embrapa, 1994). Essas ações, regionalizadas e integradas, são implementadas por meio de três classes de ensaios: ensaio de observação de linhagens (EO), ensaios comparativos preliminares de rendimento (ECP), e ensaios comparativos avançados de rendimento (ECA).

Nos EOs são inicialmente avaliadas todas as linhagens promissoras que anualmente se tornam disponíveis, principalmente como resultado das atividades dos programas de desenvolvimento de linhagens existentes no país. As linhagens selecionadas pela análise regional desses ensaios constituem no ano seguinte os ECPs, que são conduzidos em maior número de locais na região e com repetições por local. Com a avaliação detalhada da análise conjunta dos ECPs, selecionam-se as linhagens de melhor desempenho em relação a todas as características de interesse, inclusive em relação à qualidade de grãos, para continuarem a ser avaliadas nos ECAs.

Os ensaios comparativos avançados são instalados geralmente em delineamentos de blocos ao acaso, com quatro repetições, e em vários locais da região, utilizando tanto áreas das estações experimentais como áreas de lavouras cedidas pelos agricultores. As informações fornecidas pelos ensaios, principalmente pelos ECAs, são decisivas para a identificação de linhagens que apresentam maior potencial para serem liberadas como novas cultivares.

O objetivo do presente trabalho foi avaliar os progressos genéticos propiciados pelo melhoramento de arroz de sequeiro no Estado do Amapá, no período de 1990 a 1996.

\section{MATERIAL E MÉTODOS}

Os genótipos foram avaliados no ecossistema de mata de terra firme secundária (capoeira) do município de Mazagão, AP, localizado a $0^{\circ} 7^{\prime}$ de latitude Sul, $51^{\circ} 17^{\prime}$ de longitude Oeste e $15 \mathrm{~m}$ de altitude. O clima da região é do tipo Ami, segundo a classificação de Köppen, temperatura média anual de $27^{\circ} \mathrm{C}$, umidade relativa do ar de $82 \%$ e precipitação pluvial anual de $2.300 \mathrm{~mm}$, com as chuvas distribuídas de dezembro a julho. O solo da região é um Latossolo Amarelo de baixa fertilidade natural.

Os ensaios comparativos preliminares (ECPs) começaram a ser conduzidos no ano agrícola 1991/92, sendo a parcela constituída de cinco linhas de $5,10 \mathrm{~m}$ de comprimento no espaçamento de $0,30 \mathrm{~m} \times 0,30 \mathrm{~m}$ e densidade de semeadura de cinco sementes por cova, sendo a área útil formada pelas três linhas centrais, deixando-se $0,30 \mathrm{~m}$ nas extremidades. No ano seguinte, 1992/93, a parcela era formada de quatro linhas de 4,0 m de comprimento espaçadas de $0,30 \mathrm{~m}$ e densidade de semeadura de 60 sementes por metro linear, sendo a área útil formada pelas duas linhas centrais, deixando-se 0,50 m nas extremidades. A partir de 1993/94, os ECPs foram instalados com a parcela de quatro linhas de $5,0 \mathrm{~m}$ de comprimento, espaçamento de $0,40 \mathrm{~m}$ entre linhas e mesma densidade de semeadura do ano anterior. Todos os ECPs eram constituídos por três repetições.

Os ensaios comparativos avançados (ECAs) foram conduzidos a partir de 1990/91, com a parcela constituída de seis linhas de 5,0 $\mathrm{m}$ de comprimento espaçadas de $0,30 \mathrm{~m}$, densidade de semeadura de 80 sementes por metro linear e área útil formada pelas quatro linhas centrais, deixando-se $0,50 \mathrm{~m}$ nas extremidades. No ano de 1991/92, o espaçamento e densidade de semeadura foram os mesmos do ECP desse ano, e o número de linhas da parcela e da área útil iguais aos do ECA do ano anterior. Em 
1992/93, a parcela passou a ser constituída de cinco linhas de 5,0 m de comprimento espaçadas de $0,30 \mathrm{~m}$, densidade de semeadura de 60 sementes por metro linear e área útil formada pelas três linhas centrais, deixando-se $0,50 \mathrm{~m}$ nas extremidades. A partir de 1993/94 a parcela e a área útil da parcela permaneceram com os mesmos números de linhas e densidade de semeadura do ano de 1992/93, entretanto o espaçamento foi modificado para $0,40 \mathrm{~m}$ entre linhas. Todos os ECAs foram compostos por quatro repetições.

Foram utilizados dados de sete ECAs e cinco ECPs, conduzidos em áreas experimentais da Embrapa-CPAF-AP, nos anos agrícolas 1990/91 a 1995/96. Dos ECPs, foram consideradas apenas as informações das linhagens selecionadas para avaliação nos ECAs.

Além de duas testemunhas (IAC 47 e BR 4), 82 novas linhagens foram contempladas neste trabalho, as quais haviam sido submetidas à avaliação de produção de grãos, floração média (número de dias entre o plantio e a floração média), altura de planta e classe de grãos, além de incidência de acamamento e de doenças (brusone foliar, mancha-parda e escaldadura). Tais avaliações foram feitas de acordo com o manual de métodos de pesquisa em arroz, organizado pela Embrapa (1977).

Utilizando o procedimento GLM do SAS (SAS Institute, 1985), foram feitas as análises de variância conjuntas de todos os ensaios considerados e estimadas as médias das linhagens e testemunhas, ajustadas para efeito de ano (A), ensaio dentro de ano (E/A) e de repetição dentro de ensaio dentro de ano (R/E/A). A matriz de covariância do vetor de médias estimadas $(\mathrm{Y})$ foi obtida por:

$\hat{V}(\hat{V})=\mathrm{A}\left(\mathrm{X}^{\prime} \mathrm{X}\right)^{-} \mathrm{A}^{\prime} \mathrm{Q}$ Resíduo, em que:

A: matriz de coeficientes das soluções, tal que $\hat{Y}=\mathrm{A} \theta^{0}$ (conjunto de funções estimáveis), sendo $\theta^{0} \mathrm{o}$ vetor de soluções de quadrados mínimos do modelo estatístico utilizado;

$\left(\mathrm{X}^{\prime} \mathrm{X}\right)^{-}$: inversa generalizada da matriz $\mathrm{X}^{\prime} \mathrm{X}$, fornecida, como $\theta^{0}$ pelo procedimento GLM do SAS; $X$ é a matriz de coeficientes dos parâmetros do modelo adotado;

QMResíduo: estimador do quadrado médio residual da análise de variância.

Para obtenção dos ganhos de produção de grãos, utilizou-se o vetor de médias ajustadas e suas respectivas estimativas de variâncias e covariâncias e, desse modo, foram feitas as seguintes avaliações: comparação das médias dos grupos de linhagens anualmente introduzidas $\left(\mathrm{G}_{\mathrm{int}}\right)$ ou eliminadas $\left(\mathrm{G}_{\mathrm{eli}}\right)$; comparação dos contrastes $\mathrm{G}_{\text {int }}$ vs $\mathrm{G}_{\text {eli }}$, dentro de cada ano, e estimação do ganho genético médio por meio do método de Breseghello (1995).
$\mathrm{Na}$ avaliação do potencial das linhagens selecionadas adotou-se o seguinte procedimento: quanto às características floração média e altura de planta, além de produção de grãos, foram estimados os parâmetros coeficiente de determinação genética (b), coeficiente de variação genética $\left(\mathrm{CV}_{\mathrm{g}}\right)$ e índice de variação $(\mathrm{q})$, para o grupo de linhagens selecionadas e que continuaram em avaliação em 1996/97, incluindo a testemunha original mais produtiva (IAC 47).

O coeficiente de determinação genética (b), como a herdabilidade, determina quanto da variação fenotípica pode ser atribuída a causas genéticas. Deve ser empregado, conforme Rangel et al. (1991), quando os tratamentos (materiais genéticos) são fatores fixos, não constituindo, portanto, amostras de uma determinada população. Foi obtido por:

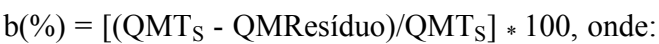

$\mathrm{QMT}_{\mathrm{S}}$ : quadrado médio dos $\mathrm{t}_{\mathrm{s}}$ tratamentos (linhagens) selecionados, que, por sua vez, foi obtido, conforme Searle (1971), pela expressão:

$\mathrm{QMT}_{\mathrm{S}}=\left\{\left(\mathrm{B} \theta^{0}\right)^{\prime}\left[\mathrm{B}\left(\mathrm{X}^{\prime} \mathrm{X}\right)^{-} \mathrm{B}^{\prime}\right]^{-1}\left(\mathrm{~B} \theta^{0}\right)\right\} /\left(\mathrm{t}_{\mathrm{s}}-1\right)$, em que:

$\mathrm{B}$ : matriz de contrastes dos efeitos de tratamentos selecionados, exemplificada por:

\begin{tabular}{|c|c|c|c|c|c|c|c|c|c|c|c|c|c|}
\hline \multicolumn{3}{|c|}{$[\mathrm{A}, \mathrm{E} / \mathrm{A}}$, & \multicolumn{3}{|c|}{$\mathrm{R} / \mathrm{E} / \mathrm{A}][$} & & \multicolumn{7}{|c|}{ Tratamentos } \\
\hline & & & & & & $t_{\mathrm{s} 1}$ & & $t_{\mathrm{s} 2}$ & $t_{s 3}$ & $t_{\mathrm{s} 4}$ & & $t_{s=22}$ & $t_{s=23}$ \\
\hline 0 & 0 & 0 & ... 0 & 0 & $\ldots$ & 1 & $\ldots$ & -1 & 0 & ... 0 & ... & 0 & $\ldots 0$ \\
\hline $\mathrm{B}=0$ & 0 & 0 & ... 0 & 0 & $\ldots$ & 0 & $\ldots$ & 1 & -1 & ... 0 & $\ldots$ & 0 & ... 0 \\
\hline 0 & 0 & 0 & ... 0 & 0 & $\ldots$ & 0 & $\ldots$ & 0 & 1 & $\ldots-1$ & $\ldots$ & 0 & ... 0 \\
\hline$\ldots$ & $\ldots$ & & $\ldots$ & $\ldots$ & $\ldots$ & $\cdots$ & $\cdots$ & $\cdots$ & $\ldots$ & $\begin{array}{lll}\ldots & \ldots\end{array}$ & $\ldots$ & $\ldots$ & $\begin{array}{lll}\ldots & \ldots\end{array}$ \\
\hline 0 & 0 & & $\ldots 0$ & 0 & $\ldots$ & 0 & $\ldots$ & 0 & 0 & $\begin{array}{ll}\ldots & 0\end{array}$ & $\ldots$ & 1 & $\begin{array}{lll}\ldots & -1\end{array}$ \\
\hline
\end{tabular}

O coeficiente de variação genética $\left(\mathrm{CV}_{\mathrm{g}}\right)$ foi obtido pela expressão:

$\mathrm{CV}_{\mathrm{g}}(\%)=\left\{\left[\left(\mathrm{QMT}_{\mathrm{S}}-\mathrm{QMResíduo}\right) / \mathrm{k}\right]^{0,5} / \hat{m}_{\mathrm{S}}\right\} * 100$, onde: $\hat{m}_{\mathrm{S}}$ : estimador da média das linhagens selecionadas, inclusive das testemunhas;

$\mathrm{k}$ : coeficiente do componente quadrático referente a tratamentos (linhagens e testemunhas) na esperança de $\mathrm{QMT}_{\mathrm{S}}$, estimado por:

$\mathrm{k}=\left[\mathrm{n} \ldots-\left(\sum_{i=1}^{t_{s}} \mathrm{n}_{\mathrm{i} . .}{ }^{2} / \mathrm{n} \ldots\right)\right] /\left(\mathrm{t}_{\mathrm{s}}-1\right)$, onde:

n...: total de observações, considerando apenas os tratamentos selecionados;

$\mathrm{n}_{\mathrm{i}} .$. : total de observações para o i-ésimo tratamento selecionado $\left(i=1,2 \ldots t_{s}\right)$.

O índice de variação (q) foi obtido, conforme Vencovsky (1978), por: $\mathrm{q}=\mathrm{CV}_{\mathrm{g}} / \mathrm{CV}_{\mathrm{e}}$, sendo:

$\mathrm{CV}_{\mathrm{e}}$ : coeficiente de variação experimental.

Pesq. agropec. bras., Brasília, v.34, n.9, p.1623-1632, set. 1999 


\section{RESULTADOS E DISCUSSÃO}

As análises de variância em relação às características produção de grãos (PROD), número de dias para a floração média (FLOR) e altura de planta (ALT) revelaram coeficientes de variação experimental de, respectivamente, $17,7 \%, 4,0 \%$ e $6,5 \%$. Em todos os casos, a aplicação do teste $\mathrm{F}$ rejeitou a hipótese de igualdade dos efeitos de tratamento, em níveis de probabilidade inferiores a $1 \%$. O maior coeficiente de variação obtido em PROD já era esperado, uma vez que se trata de característica mais sensível à variação ambiente do que FLOR e ALT (Jennings et al., 1979), mas ainda pode ser classificado como de magnitude intermediária (Pimentel-Gomes, 1987) e comparável aos rotineiramente obtidos em experimentação com arroz de sequeiro.

\section{Ganhos em produção de grãos}

$\mathrm{Na}$ Tabela 1 encontram-se relacionadas as estimativas de médias dos grupos de linhagens que foram anualmente introduzidos $\left(\mathrm{G}_{\mathrm{int}}\right)$ e eliminados $\left(\mathrm{G}_{\text {eli }}\right)$ dos ensaios comparativos avançados. Nenhum grupo de linhagem superou significativamente as testemunhas tradicionais (BR 4 e IAC 47), mesmo sendo a magnitude da média estimada do $G_{\text {int }}$ de
1996/97 superior à das referidas testemunhas em $34,2 \%$. Isto ocorreu em decorrência do fato de as testemunhas terem sido eliminadas dos ensaios logo no início do período estudado; cada uma delas foi avaliada em apenas um ano agrícola. Com pequeno número de observações, contrastes relativamente elevados envolvendo as testemunhas não atingiram os níveis de significância preestabelecidos.

Observou-se, contudo, uma variação entre os $\mathrm{G}_{\text {int }}$ 's, sendo o de 1992/93 significativamente mais produtivo que o do ano anterior. Nesse primeiro grupo encontravam-se linhagens cujos rendimentos médios situaram-se acima de 3,0 t/ha (CNA 7459, CNA 7284, CNA 5598, CNA 6196 e CNA 6199), todas eliminadas no ano seguinte por terem se revelado pouco promissoras, notadamente quanto a características de grãos. Como conseqüência, constata-se na Tabela 1 que o $\mathrm{G}_{\text {eli }}$ de 1993/94 é o mais produtivo entre os grupos de linhagens eliminados.

A partir de 1993/94 começaram a ser incluídas nos ECAs linhagens extraídas de cruzamentos realizados no final da década de 80 , objetivando melhorar a qualidade de grão do arroz de sequeiro, em razão da acentuada preferência do mercado pelos grãos de classe longo fino ou agulhinha. As primeiras fontes de qualidade de grãos utilizadas

TABELA 1. Médias de produção de grãos (kg/ha) dos grupos de linhagens anualmente introduzidos ou eliminados nos ensaios comparativos avançados, conduzidos no Amapá, no período de 1990 a 1996. Apresentam-se também as relações entre médias desses grupos e a média das cultivares testemunhas, expressas em percentagem (\%/Test), bem como os contrastes entre as médias dos grupos introduzidos e eliminados, dentro de ano ${ }^{1}$.

\begin{tabular}{|c|c|c|c|c|c|}
\hline \multirow{2}{*}{$\begin{array}{c}\text { Ano } \\
\text { agrícola }\end{array}$} & \multicolumn{2}{|c|}{ Grupos introduzidos $\left(\mathrm{G}_{\text {int }}\right)$} & \multicolumn{2}{|c|}{ Grupos eliminados $\left(\mathrm{G}_{\mathrm{eli}}\right)$} & \multirow{2}{*}{$\begin{array}{l}\text { Contraste } \\
\mathrm{G}_{\text {int }}-\mathrm{G}_{\mathrm{eli}}\end{array}$} \\
\hline & Produção (kg/ha) & $\% /$ Test & Produção (kg/ha) & $\% /$ Test & \\
\hline 1990/91 & $2.430 \mathrm{ab}$ & 115,9 & - & - & - \\
\hline $1991 / 92$ & $2.180 \mathrm{~b}$ & 104,0 & $2.242 \mathrm{bcd}$ & 106,9 & -62 \\
\hline $1992 / 93$ & $2.688 \mathrm{ab}$ & 128,2 & $2.087 \mathrm{~cd}$ & 99,5 & $601^{2}$ \\
\hline $1993 / 94$ & $2.439 \mathrm{ab}$ & 116,3 & $2.815 \mathrm{a}$ & 134,2 & $-376^{2}$ \\
\hline $1994 / 95$ & $2.560 \mathrm{ab}$ & 122,1 & $2.119 \mathrm{~d}$ & 101,0 & $441^{2}$ \\
\hline $1995 / 96$ & $2.744 \mathrm{ab}$ & 130,8 & $2.538 \mathrm{abc}$ & 121,0 & 206 \\
\hline $1996 / 97$ & $2.814 \mathrm{a}$ & 134,2 & $2.677 \mathrm{ab}$ & 127,7 & 137 \\
\hline \multicolumn{5}{|c|}{ Média dos contrastes $\mathrm{G}_{\text {int }}-\mathrm{G}_{\text {eli }} \pm$ desvio-padrão $(\mathrm{kg} / \mathrm{ha})$} & $157,8 \pm 65,6$ \\
\hline
\end{tabular}

Pesq. agropec. bras., Brasília, v.34, n.9, p.1623-1632, set. 1999 
foram de baixa adaptação ao sistema de sequeiro (Colômbia 1, IR 6223-43-3, Labelle, Lebonnet, Camponi, Ciwini, Ceyswoni, Lemont, Newrex, etc.), trazendo dificuldades adicionais na seleção de linhagens de maior potencial produtivo que as selecionadas anteriormente. A primeira conseqüência desse novo enfoque foi uma redução da capacidade produtiva das novas linhagens, o que fica comprovado quando se compara o rendimento médio do $\mathrm{G}_{\text {int }}$ de 1993/94 com o do ano anterior.

No ano agrícola seguinte, ou seja 1994/95, o desempenho do programa quanto ao ganho em produção de grãos já dava sinais de recuperação. A média de rendimento do ECA daquele ano deve ter sido positivamente influenciada pelo fato de o novo $\mathrm{G}_{\text {int }}$ ser significativamente mais produtivo, que o grupo eliminado, em $441 \mathrm{~kg} / \mathrm{ha}$. Nos dois anos subseqüentes os contrastes $G_{\text {int }} v \mathrm{G}_{\text {eli }}$ continuaram positivos, embora não-significativos pelos testes estatísticos empregados. Em média, os grupos introduzidos nos ECAs de 1991/92 a 1996/97 superaram os eliminados em 157,8 kg/ha/ano, com um desvio-padrão de $65,6 \mathrm{~kg} / \mathrm{ha}$. Houve, por conseguinte, ganhos significativos em produção de grãos, no processo anual de substituição, nos ECAs, de linhagens pouco promissoras por outras selecionadas, em sua maioria, nos ECPs.

$\mathrm{Na}$ comparação de médias oriundas de dados desbalanceados, a cada contraste encontra-se associada uma diferença mínima significativa, pois suas variâncias são variáveis, dependendo do número de observações que deram origem às estimativas e da magnitude e sentido da covariação existente entre elas. Por isso, de dois contrastes observados de magnitudes diferentes, o menor pode ser considerado significativo e o maior, não. Observa-se na Tabela 1 que o $\mathrm{G}_{\text {int }}$ de 1991/92 se revelou significativamente menos produtivo que o de 1992/93, mas não em relação aos de 1995/96 e 1996/97, apesar de suas estimativas de médias serem de magnitude ainda mais elevadas. Da mesma forma, a média estimada do $\mathrm{G}_{\text {eli }}$ de 1995/96 diferiu significativamente da média do ano anterior, mas não da de 1992/93, que foi de magnitude inferior.

Na Tabela 2 estão listadas as estimativas de médias dos grupos de linhagens que constituíam os ECAs (GLE) dos anos do período avaliado, bem como as estimativas de ganhos anuais observados (GAO) e de ganho anual médio (GAM). É importante salientar que a média de um determinado GLE não se originou apenas das observações obtidas no ano correspondente. Em virtude de seu método de estimação, recuperam-se as informações disponíveis em outros anos, inclusive nos ensaios comparativos preliminares. A tendência crescente das médias dos GLEs dos anos contemplados refletem o balanço positivo representado pela médias dos contrastes $G_{\text {int }}-G_{\text {eli já }}$ comentado, e que se revelou significativa $(p<0,05)$. Observou-se ainda que, nos anos mais recentes, os desvios-padrão das médias foram menores que os das médias obtidas no início do período, devido ao maior número de observações advindas de um maior número de ensaios e de um maior número de linhagens comuns entre anos consecutivos.

Em todo o período, constatou-se ganho negativo em apenas um ano, 1993/94, que, como comentado anteriormente, deveu-se à inclusão nos ensaios das primeiras linhagens com classe de grão agulhinha, que eram de menor capacidade produtiva. Naquele ano, o contraste $G_{\text {int }}-G_{\text {eli }}$ foi negativo e altamente significativo $(p<0,01)$. Em dois anos agrícolas (1992/93 e 1994/95), por sua vez, os ganhos observados superaram em mais de três vezes seus respectivos desvios-padrão, podendo ser considerados, portanto, altamente significativos (El-Rouby, 1973).

TABELA 2. Estimativas de médias ajustadas de produção de grãos dos grupos de linhagens componentes dos ensaios comparativos avançados de arroz de sequeiro (GLE) dos anos de 1990/91 a 1995/96, ganhos anuais observados (GAO) e ganho anual médio, com respectivos desvios-padrão.

\begin{tabular}{llc}
\hline GLE & $\begin{array}{c}\text { Médias } \\
(\mathrm{kg} / \mathrm{ha})\end{array}$ & $\begin{array}{c}\text { GAO } \\
(\mathrm{kg} / \mathrm{ha})\end{array}$ \\
\hline $1990 / 91$ & $2.386,6 \pm 131,5$ & - \\
$1991 / 92$ & $2.306,6 \pm 102,1$ & $80,1 \pm 86,7$ \\
$1992 / 93$ & $2.754,5 \pm 69,0$ & $447,9 \pm 98,9$ \\
$1993 / 94$ & $2.471,2 \pm 72,4$ & $-283,3 \pm 107,6$ \\
$1994 / 95$ & $2.674,2 \pm 68,1$ & $203,0 \pm 60,9$ \\
$1995 / 96$ & $2.724,1 \pm 50,9$ & $50,9 \pm 50,4$ \\
\hline \multicolumn{2}{l}{ Ganho anual médio } & $83,0 \pm 26,1$ \\
\hline
\end{tabular}

Pesq. agropec. bras., Brasília, v.34, n.9, p.1623-1632, set. 1999 
O ganho anual médio em produtividade estimado pelo método de Breseghello (1995) foi de $83,0 \mathrm{~kg} / \mathrm{ha}$ e significativo pelo teste $\mathrm{t}$, a $1 \%$ de probabilidade. Em relação à média $(2.387 \mathrm{~kg} / \mathrm{ha})$ do GLE do início do período estudado (ano agrícola 1990/91), esse GAM de 83,0 kg/ha representa, percentualmente, um incremento médio de 3,5\%/ano na produtividade. A título de comparação, relacionam-se os resultados obtidos também com arroz de sequeiro por Soares (1992), em Minas Gerais, e Abbud (1991), no Paraná, que foram de, respectivamente, $3,0 \%$ e $1,3 \%$ ao ano. Com o arroz irrigado, as estimativas de ganho têm sido ainda menores (Soares \& Ramalho, 1993; Breseghello, 1995). Ainda no Brasil, programas de melhoramento de outras culturas têm revelado desempenho também inferiores. Vencovsky et al. (1988), utilizando dados de ensaios de milho, de um período de 20 anos, obtiveram estimativas de $2,2 \%$, para populações, e de 1,7\%, para os híbridos comerciais. O programa de melhoramento de soja desenvolvido no Paraná, no período de 1981 a 1986, apresentou um ganho médio de $1,8 \%$ com as linhagens precoces e de $1,3 \%$ com as semiprecoces (Toledo et al., 1990). Rodrigues (1990), utilizando dados dos ensaios nacionais de sorgo, desenvolvidos de 1974 a 1988, estimou ganhos anuais de 1,5\%.

A estimativa de ganho em produção de grãos aqui obtida poderia ter sido ainda mais favorável não fosse a necessidade de se considerar também como objetivo maior a seleção de outras características, tais como qualidade de grãos e resistência a enfermidades, notadamente mancha-parda, escaldadura e mancha-de-grãos. A sua magnitude relativamente elevada constitui, de qualquer forma, uma demonstração da escolha acertada da estratégia adotada de se desenvolver na Região Norte um programa cooperativo de melhoramento de arroz, que permite utilizar procedimentos seletivos baseados em informações compartilhadas por um grupo de pesquisadores que exploram áreas com razoável grau de similaridade.

\section{Avaliação do potencial das linhagens selecionadas}

No final do período (1996), 21 linhagens foram selecionadas e continuaram em avaliação em
1996/97. Nesse grupo incluem-se algumas variedades, como Araguaia e Progresso, que, para facilidade de redação, serão todas denominadas de linhagens. Das linhagens selecionadas, nove provieram do ECA (Araguaia, CNA 7706, Progresso, IAC 1359, IAC 1364, CNA 8096, CNA 8386, CNA 8390 e CNA 8394) e onze do ECP de 1995/96 (CNA 7475, CNA 8170, CNA 8172, CNA 8304, CNA 8305, CNA 8436, CNA 8437, CNA 8441, CNA 8519, CNA 8520 e IAC 1477). A Araguaia e a Xingu foram incluídas em ambos os ensaios, permitindo, portanto, a avaliação conjunta dos dois subgrupos de linhagens, cujos resultados são apresentados na Tabela 3.

Além de produção de grãos (PROD), floração média (FLOR) e altura de planta (ALT), que foram submetidos à analise de variância, encontram-se na Tabela 3 as médias das observações relativas à incidência de acamamento, mancha-parda, brusone foliar e escaldadura, além de classe de grãos.

A cultivar Xingu é recomendada para o plantio no Amapá desde 1992. Em relação à IAC 47, caracteriza-se por ser menos suscetível ao acamamento em áreas mais férteis, segundo avaliações realizadas em outros Estados da Região Norte. Não se dispõe de informações de acamamento da IAC 47 na Tabela 3 porque participara dos ensaios apenas em 1992/93, ano em que os ensaios não foram adubados e não se avaliou incidência de acamamento. A Xingu constou de todos os ensaios realizados, inclusive como testemunha dos ECPs, e por essa razão foi utilizada como testemunha para as avaliações.

Nenhuma das linhagens selecionadas se mostrou significativamente mais tardia que a testemunha Xingu. Três linhagens, contudo, podem ser consideradas precoces: CNA 8172, CNA 8304 e IAC 1477. Em relação à altura, observou-se também que nenhuma linhagem foi significativamente mais alta que a Xingu, sendo, por outro lado, cinco delas (Progresso, CNA 8170, CNA 8436, CNA 8437 e CNA 8519) mais baixas, e provavelmente por essa razão não acamaram. Em relação a doenças, observaram-se, de uma maneira geral, baixos níveis de incidência em todas as linhagens selecionadas, com exceção de escaldadura na IAC 1364, CNA 7475, CNA 8519 e CNA 8520, que 
apresentaram notas médias de incidência relativamente altas (entre 4,0 e 5,0). São linhagens que se apresentam pouco promissoras para áreas sujeitas à ocorrência de escaldadura, como nos casos de sucessão à cultura da soja.

$\mathrm{Na}$ Tabela 3 observa-se, ainda, o grande progresso conseguido com a seleção em classe de grãos. A classificação dos grãos (beneficiados) foi feita comparando, visualmente, os grãos beneficiados das linhagens com padrões preestabelecidos pelo laboratório de qualidade de grãos da Embrapa-Centro Nacional de Pesquisa de Arroz e Feijão. Segundo esses padrões, grãos de classe 1 assemelham-se, em forma e dimensões, aos da Bluebelle, cultivar de origem americana já intensivamente cultivada no Rio Grande do Sul. Os grãos das cultivares tradicionais de arroz de sequeiro brasileiro, como IAC 47, Rio Paranaíba, Guarani e Xingu, são tipicamente de classe 7,0. Grãos com nota 4,0 em classe de grãos já se classificam como agulhinha e correspondem, por exemplo, aos grãos da cultivar Metica 1, amplamente utilizada nas várzeas do Estado do Tocantins, com irrigação por inundação. Grãos de classe 1,0 a 3,0 correspondem aos tipos preferidos atualmente pelo consumidor brasileiro. Desta forma, todas as linhagens selecionadas, com exceção da Araguaia e das

TABELA 3. Estimativas de médias de produção de grãos (PROD), floração média (FLOR), altura de planta (ALT), incidência de acamamento (ACA), mancha-parda (MP), brusone nas folhas (BF) e escaldadura foliar (ESC), além de informações preliminares de classe de grãos (CV) ${ }^{1}$, das linhagens selecionadas e que continuam em avaliação em 1996/97².

\begin{tabular}{lcccccccc}
\hline Linhagens & PROD & FLOR & ALT & ACA $^{3}$ & MP $^{3}$ & BF $^{3}$ & ESC $^{3}$ & CV $^{3}$ \\
& $(\mathrm{~kg} / \mathrm{ha})$ & $(\mathrm{dias})$ & $(\mathrm{cm})$ & $(1-9)$ & $(1-9)$ & $(1-9)$ & $(1-9)$ & $(1-8)$ \\
\hline Araguaia & $2.437 \mathrm{a}$ & $82 \mathrm{a}$ & $116 \mathrm{a}$ & 1,4 & 1,1 & 1,1 & 3,6 & 5,0 \\
CNA 6843-1 & $3.188 \mathrm{a}$ & $82 \mathrm{a}$ & $104 \mathrm{a}$ & 1,0 & 1,6 & 1,6 & 2,0 & 3,1 \\
CNA 7706 & $2.633 \mathrm{a}$ & $87 \mathrm{a}$ & $111 \mathrm{a}$ & 1,0 & 1,4 & 1,5 & 1,8 & 3,3 \\
Progresso & $2.958 \mathrm{a}$ & $83 \mathrm{a}$ & $98 \mathrm{~b}$ & 1,0 & 2,5 & 2,1 & 3,8 & 3,1 \\
IAC 1359 & $2.659 \mathrm{a}$ & $80 \mathrm{a}$ & $112 \mathrm{a}$ & 1,3 & 1,0 & 2,3 & 3,3 & 2,7 \\
IAC 1364 & $3.033 \mathrm{a}$ & $80 \mathrm{a}$ & $102 \mathrm{a}$ & 1,2 & 1,2 & 1,5 & 4,6 & 3,0 \\
CNA 8096 & $2.263 \mathrm{a}$ & $86 \mathrm{a}$ & $108 \mathrm{a}$ & 1,1 & 3,0 & 1,3 & 2,6 & 4,0 \\
CNA 8386 & $3.384 \mathrm{a}$ & $83 \mathrm{a}$ & $116 \mathrm{a}$ & 1,1 & 2,4 & 1,4 & 3,3 & 2,0 \\
CNA 8390 & $2.763 \mathrm{a}$ & $84 \mathrm{a}$ & $103 \mathrm{a}$ & 1,0 & 1,2 & 2,1 & 3,6 & 4,0 \\
CNA 8394 & $3.236 \mathrm{a}$ & $87 \mathrm{a}$ & $118 \mathrm{a}$ & 1,1 & 2,9 & 2,4 & 3,3 & 2,0 \\
CNA 7475 & $2.842 \mathrm{a}$ & $83 \mathrm{a}$ & $108 \mathrm{a}$ & 1,0 & 2,6 & 1,1 & 4,7 & 3,0 \\
CNA 8170 & $2.974 \mathrm{a}$ & $88 \mathrm{a}$ & $100 \mathrm{~b}$ & 1,0 & 2,6 & 1,8 & 3,3 & 2,1 \\
CNA 8172 & $2.503 \mathrm{a}$ & $76 \mathrm{~b}$ & $109 \mathrm{a}$ & 1,0 & 1,7 & 1,1 & 3,8 & 4,0 \\
CNA 8304 & $2.758 \mathrm{a}$ & $76 \mathrm{~b}$ & $106 \mathrm{a}$ & 1,0 & 1,0 & 1,1 & 2,0 & 3,8 \\
CNA 8305 & $2.824 \mathrm{a}$ & $81 \mathrm{a}$ & $105 \mathrm{a}$ & 1,0 & 1,7 & 1,1 & 1,8 & 3,8 \\
CNA 8436 & $2.851 \mathrm{a}$ & $80 \mathrm{a}$ & $93 \mathrm{~b}$ & 1,0 & 1,3 & 1,8 & 3,3 & 2,2 \\
CNA 8437 & $3.188 \mathrm{a}$ & $87 \mathrm{a}$ & $99 \mathrm{~b}$ & 1,0 & 1,7 & 1,1 & 3,8 & 2,2 \\
CNA 8441 & $3.085 \mathrm{a}$ & $88 \mathrm{a}$ & $108 \mathrm{a}$ & 1,0 & 1,0 & 1,2 & 3,0 & 1,6 \\
CNA 8519 & $2.258 \mathrm{a}$ & $81 \mathrm{a}$ & $101 \mathrm{~b}$ & 1,0 & 2,7 & 1,1 & 4,8 & 1,4 \\
CNA 8520 & $2.429 \mathrm{a}$ & $87 \mathrm{a}$ & $112 \mathrm{a}$ & 1,0 & 3,3 & 1,8 & 5,3 & 3,4 \\
IAC 1477 & $3.242 \mathrm{a}$ & $73 \mathrm{~b}$ & $119 \mathrm{a}$ & 1,0 & 2,1 & 1,0 & 4,0 & 3,0 \\
Xingu & $2.595 \mathrm{a}$ & $85 \mathrm{a}$ & $117 \mathrm{a}$ & 2,8 & 1,5 & 1,1 & 3,0 & 7,0 \\
IAC 47 & $2.543 \mathrm{a}$ & $86 \mathrm{a}$ & $125 \mathrm{a}$ & - & - & - & - & 7,0 \\
\hline C.V. (\%) & 17,72 & 4,03 & 6,53 & - & - & - & - & - \\
\hline
\end{tabular}

${ }^{1}$ CV: classificação visual (1 (classe de Bluebelle, desejado) a 8 (IRAT 13 )).

${ }^{2}$ Médias seguidas pela letra a não diferem significativamente da média da Xingu (testemunha), a 5\% pelo teste de Dunnet.

3 Os menores valores são os desejados. 
testemunhas Xingu e IAC 47, produzem grãos de classe agulhinha ou, pelo menos, próximo ao padrão dela.

Em relação à produção de grãos, observou-se que, entre as linhagens selecionadas, nenhuma estimativa de produção de grãos se revelou significativamente maior (ou menor) que a da testemunha Xingu $(2.595 \mathrm{~kg} / \mathrm{ha})$. A aplicação do teste $\mathrm{F}$ ao quadrado médio de tratamentos selecionados (incluindo a Xingu) havia, contudo, rejeitado a hipótese de igualdade dos efeitos de tratamento, em níveis de probabilidade inferiores a $1 \%$, evidenciando que deveria existir, pelo menos, algum tipo de contraste significativo entre os tratamentos selecionados. Decidiuse, por isso, avaliar as possíveis significâncias das diferenças entre cinco grupos de tratamentos, constituídos pela testemunha original (IAC 47), testemunha atual (Xingu), pelas sete linhagens mais produtivas, sete linhagens de produção intermediária e sete linhagens menos produtivas. As médias desses grupos estão listadas na Tabela 4, na qual se verifica que o primeiro grupo de linhagens produziu $23,1 \%$ a mais que a testemunha Xingu, diferindo significativamente desta e do grupo de linhagens menos produtivas. Há, por conseguinte, variação genética relevante dentro das linhagens selecionadas, sendo possível identificar linhagens pertencentes provavelmente ao primeiro grupo, mais produtivas que a testemunha, desde que se aumente o poder dos testes estatísticos pela melhoria do controle da variação ambiente nos experimentos e, principalmente, pelo aumento do número de observações para os tratamentos de interesse. É oportuno salientar que no grupo mais produtivo há linhagens que sobressaem pelas características de grãos e de menor incidência de doenças e de acamamento, como a CNA 6843-1, CNA 8386, CNA 8394, CNA 8170 e CNA 8441.

As estimativas do coeficiente de determinação genética (b), coeficiente de variação genética $\left(\mathrm{CV}_{\mathrm{g}}\right)$ e índice de variação (q) em produção de grãos das linhagens selecionadas, incluindo as testemunhas Xingu e IAC 47, são apresentadas na Tabela 5. A estimativa de b de $47,80 \%$ pode ser considerada de magnitude apenas moderada, já que se origina de variação entre médias. Em populações de ampla variação genética, estimativas de $\mathrm{h}^{2}$ (herdabilidade), similar a b, têm sido bem mais elevadas, quando baseadas em médias de famílias de indivíduos bem relacionados geneticamente, como $\mathrm{S}_{1}, \mathrm{~S}_{2}$, etc. (Morais et al., 1997). Neste trabalho, estimou-se b para um grupo de indivíduos selecionados e, nesse caso, normalmente se esperam estimativas de magnitude moderada em parâmetros de variação, como o coeficiente de determinação genética, com respeito à produção de grãos, que, adicionalmente, caracteriza-se por ser bastante influenciado pela variação ambiental.

Em consonância com o fato de FLOR e ALT terem apresentado estimativas de coeficiente de variação experimental menores que a relativa à PROD, observou-se que apresentaram, em conseqüência, maiores estimativas de b, o que demonstra que tais características são menos influenciadas pelos fatores ambientais. Acresce-se, ainda, o fato de que normalmente se exerce maior pressão de seleção sobre a característica PROD do que sobre FLOR e ALT em que geralmente se tolera uma maior amplitude de variação nos grupos selecionados.

TABELA 4. Estimativas de médias de produção de grãos (PROD) de três grupos das linhagens selecionadas e das testemunhas Xingu e IAC 47 e percentual dessas estimativas em relação às da primeira testemunha.

\begin{tabular}{lcc}
\hline Grupos de linhagens & PROD $(\mathrm{k} / \mathrm{ha})^{1}$ & $\% / \mathrm{Xingu}$ \\
\hline Grupo 1 (sete linhagens mais produtivas) & $3.194 \mathrm{a}$ & 123,1 \\
Grupo 2 (sete linhagens de produção intermediária) & $2.853 \mathrm{ab}$ & 109,0 \\
Grupo 3 (sete linhagens menos produtivas) & $2.455 \mathrm{~b}$ & 94,6 \\
Xingu (testemunha atual) & $2.595 \mathrm{~b}$ & 100,0 \\
IAC 47 (testemunha original) & $2.543 \mathrm{ab}$ & 98,0 \\
\hline
\end{tabular}

${ }^{1}$ Médias seguidas pela mesma letra não diferem significativamente pelo teste de Tukey, a $5 \%$ de probabilidade. 
Embora a estimativa de b seja menor para PROD do que para FLOR e ALT, não se espera, conforme salientam Morais et al. (1997), as menores mudanças possíveis pelo processo seletivo, quando expressas em relação à média, pois foi PROD que apresentou a maior estimativa de coeficiente de variação genética $\left(\mathrm{CV}_{\mathrm{g}}\right)$. Se fossem selecionadas, por exemplo, as cinco linhagens mais produtivas da Tabela 3 (percentual de seleção de aproximadamente $20 \%$ ), esperar-se-ia um ganho de seleção de 7,42\% $(\mathrm{G}=\mathrm{b} * \mathrm{DS}$, sendo DS: diferencial de seleção). Se, da mesma forma, fossem selecionadas, de maneira independente, as cinco linhagens mais tardias, a estimativa de aumento do ciclo seria de $4,32 \%$, ou seja, menor, apesar de a estimativa de b para FLOR ser aproximadamente de $62 \%$ superior à de PROD. A principal utilidade do parâmetro $C_{\mathrm{g}}$ é, por conseguinte, indicar a característica mais vulnerável à alteração de média, em termos percentuais, pela aplicação da seleção.

As estimativas do índice de variação (q) foram todas inferiores à unidade, indicando, segundo Vencovsky (1978), uma situação não muito favorável à seleção. Como já comentado, as estimativas obtidas aplicam-se a um grupo de linhagens que representa o fruto de um processo seletivo, em que já se tem uma expectativa de uma razoável restrição na amplitude dos parâmetros de variação. Ganhos relevantes decorrentes da seleção, nesse caso, só se verificam com a utilização de procedimentos muito eficientes de avaliação. Ainda, como observado por Morais et al. (1978), neste trabalho verificou-se a associação positiva e estreita entre b e q, ou seja, a

TABELA 5. Estimativas do coeficiente de determinação genética (b), coeficiente de variação genética $\left(\mathrm{CV}_{\mathrm{g}}\right)$, índice de variação $(q)$ das linhagens selecionadas, incluindo as testemunhas Xingu e IAC 47.

\begin{tabular}{lccc}
\hline Parâmetro & Produção (kg/ha) & Floração (dias) & Altura (cm) \\
\hline $\mathrm{b}(\%)$ & 47,80 & 77,67 & 81,68 \\
$\mathrm{CV}_{\mathrm{g}}(\%)$ & 6,88 & 3,08 & 5,76 \\
$\mathrm{q}$ & 0,39 & 0,76 & 0,88 \\
\hline
\end{tabular}

maiores valores de estimativa do primeiro corresponde também um maior valor da estimativa do segundo, e vice-versa.

\section{Recomendação de novas variedades}

A recomendação de novas variedades para cultivo constitui também um indicador adicional dos resultados favoráveis apresentados pelas atividades de melhoramento. Quatro anos após a recomendação da Xingu, a CNA 7706 foi liberada como nova variedade também no Amapá, com a denominação de Confiança. Apesar de não ser significativamente mais produtiva que aquela, caracteriza-se por uma maior resistência ao acamamento e por produzir grãos de classe longo-fino (agulhinha) e de excelente qualidade culinária. Em 1996, decidiu-se pelo lançamento, no ano seguinte, da CNA 6843-1 com o nome fantasia de Maravilha. Além de apresentar os mesmos níveis, considerados satisfatórios, de resistência ao acamamento e a enfermidades da Confiança, constitui uma das sete linhagens do grupo significativamente mais produtivo que a Xingu, sobressaindo ainda por apresentar grãos tipicamente longo-finos (agulhinha), de alto rendimento de inteiros e de excelente aparência após o beneficiamento.

\section{CONCLUSÕES}

1. O ganho genético anual em produtividade de $83,0 \mathrm{~kg} / \mathrm{ha}(3,5 \%)$ é considerado elevado em relação aos obtidos por outros programas de melhoramento genético.

2. Entre as linhagens selecionadas, há grupo significativamente mais produtivo que a cultivar testemunha de melhor desempenho.

3. Os ganhos em qualidade de grãos são elevados, sendo as melhores linhagens em avaliação classificadas como de grãos longo-finos.

4. Duas novas cultivares, Xingu e Confiança, efetivamente recomendadas no decorrer do período avaliado, permitem substanciais ganhos em resistência ao acamamento e, no caso da segunda cultivar, em qualidade de grãos.

Pesq. agropec. bras., Brasília, v.34, n.9, p.1623-1632, set. 1999 


\section{REFERÊNCIAS}

ABBUD, N.S. Melhoramento genético do arroz (Oryza sativa L.) no Estado do Paraná de 1975 a 1989. Piracicaba: ESALQ, 1991. 141p. Tese de Doutorado.

BRESEGHELLO, F. Ganhos para produtividade pelo melhoramento genético do arroz irrigado no Nordeste do Brasil. Goiânia: UFG, 1995. 93p. Tese de Mestrado.

EL ROUBY, M.M.; MORAYEM, Y.S.; NAWAR, A.A. Estimation of genetic variance and its components in maize under stress and non-stress environments. I - Planting date. Egyptian Journal of Genetics and Cytology, Giza, v.2, p.10-19, 1973.

EMBRAPA. Centro Nacional de Pesquisa de Arroz e Feijão (Goiânia, GO). Manual de métodos de pesquisa em arroz. Goiânia, 1977. 106p.

EMBRAPA. Centro Nacional de Pesquisa de Arroz e Feijão (Goiânia, GO). Programa Nacional de Avaliação de Linhagens de Arroz. Goiânia, 1994. 19p. (Embrapa-CNPAF. Documentos, 41).

JENNINGS, P.R.; COFFMAN, W.R.; KAUFFMAN, H.E. Rice improvement. Los Baños: IRRI, 1979. 186p.

LEVANTAMENTO SISTEMÁTICO DA PRODUÇÃO AGRÍCOLA. Rio de Janeiro: IBGE, v.8, n.4, abr. 1996. 68p.

MORAIS, O.P.; SANT'ANA, E.P.; CHATEL, M.; PRABHU, A.S.; CASTRO, E.M. Melhoramento genético voltado para a cultura do arroz de sequeiro. In: FERREIRA, M.E.; YAMADA, T.; MALAVOLTA, E. (Eds.). Cultura do arroz de sequeiro: fatores afetando a sua produtividade. Piracicaba: POTAFOS, 1983. p.145-178.

MORAIS, O.P. de; SILVA, J.C.; CRUZ, C.D.; REGAZZI, A.J.; NEVES, P. de C.F. Estimação de parâmetros genéticos da população de arroz irrigado CNA-IRAT 4/0/3. Pesquisa Agropecuária Brasileira, Brasília, v.32, n.4, p.421-433, abr. 1997.
PIMENTEL-GOMES, F. Curso de Estatística Experimental. 12.ed. Piracicaba: Nobel, 1987. 467p.

RANGEL, P.H.N.; CRUZ, C.D.; VENCOVSKY, R.; FERREIRA, R.P. Selection of local lowland rice cultivars based on multivariate genetic divergence. Brazilian Journal of Genetics, Ribeirão Preto, v.14, n.2, p.437-453, 1991.

RODRIGUES, J.A.S. Progresso genético e potencial de risco da cultura do sorgo granífero (Sorghum bicolor L. Moench) no Brasil. Piracicaba: ESALQ, 1990. 171p. Tese de Doutorado.

SAS INSTITUTE. SAS user's guide: statistics, version 5. 5.ed. Cary, NC, 1985. 956p.

SEARLE, S.R. Linear models. New York: John Willey, 1971. 532p.

SOARES, A.A. Desempenho do melhoramento genético do arroz de sequeiro e irrigado na década de oitenta em Minas Gerais. Lavras: ESAL, 1992. 188p. Tese de Doutorado.

SOARES, A.A.; RAMALHO, M.A.P. Estimativas do progresso genético no melhoramento do arroz (Oryza sativa L.). I. Comparação de métodos. Ciência e Prática, Lavras, v.17, n.1, p.27-34, 1993.

TOLEDO, J.F.F. de; ALMEIDA, L.A. de; KIIHL, R.A. de S.; MENOSO, O.G. Ganho genético em soja no Estado do Paraná, via melhoramento. Pesquisa Agropecuária Brasileira, Brasília, v.25, n.1, p.89-94, 1990.

VENCOVSKY, R. Herança quantitativa. In: PATERNIANI, E.; VIEGAS, G.P. (Eds.). Melhoramento e produção de milho. Campinas: Fund. Cargill, 1978. p.135-214.

VENCOVSKY, R.; MORAIS, A.R.; GARCIA, J.C.; TEIXEIRA, N.M. Progresso genético em vinte anos de melhoramento de milho no Brasil. In: CONGRESSO NACIONAL DE MILHO E SORGO, 16., 1986, Belo Horizonte. Anais. Sete Lagoas: Embrapa-CNPMS, 1988. p.300-306. 